Rapid Reviews COVID-19

\title{
Reviews of "Qualitatively \\ distinct modes of Sputnik \\ $V$ vaccine-neutralization \\ escape by SARS-CoV-2 \\ Spike variants"
}

Alexander Mentzer ${ }^{1}$, Mario Cazzola ${ }^{2}$, Maria Gabriella Matera ${ }^{3}$

${ }^{1}$ University of Oxford Hooke Library: University of Oxford, Wellcome Trust Centre for human genetics,

${ }^{2}$ University of Rome Tor Vergata Faculty of Medicine and Surgery: Universita degli Studi di Roma Tor Vergata Facolta di Medicina e Chirurgia, Experimental Medicine, Italy,

${ }^{3}$ University of Campania “Luigi Vanvitelli”, Naples, Italy

Published on: May 29, 2021

License: Creative Commons Attribution 4.0 International License (CC-BY 4.0). 
To read the original manuscript, click the link above.

Summary of Reviews: This study reports antibodies generated from Sputnik $V$ vaccination exhibit less neutralizing activity against B.1.351 and E484K variants than wildtype and B.1.1.7. Reviewers deem these findings informative, but caution more standard assays and clinical studies are necessary.

Reviewer 1 (Alexander Mentzer)

Reviewer 2 (Mario Cazzola, Maria Gabriella Matera)

$$
\begin{aligned}
& \text { RR:C19 Strength of Evidence Scale Key } \\
& \text { प्रमप = Misleading } \\
& \text { प्र००० = Not Informative } \\
& \text { प्रा पि = Potentially Informative }
\end{aligned}
$$

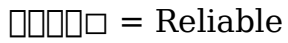

$$
\begin{aligned}
& \text { प्राप्र = Strong }
\end{aligned}
$$

To read the reviews, click the links below. 